\title{
Microarray of Recombinant Antibodies Using a Streptavidin Sensor Surface Self-Assembled onto a Gold Layer
}

BioTechniques 34:124-130 (January 2003)

\author{
P. Pavlickova, A. Knappik ${ }^{1}$ D. \\ Kambhampati $^{2}$, F. Ortigao ${ }^{2}$, \\ and H. Hug \\ University of Ulm, Ulm, \\ ${ }^{1}$ MorphoSys AG, Munich, and \\ ${ }^{2}$ ThermoHybaid GmbH, Ulm, \\ Germany
}

\begin{abstract}
We have developed a sensitive method for the detection of recombinant antibodyantigen interactions in a microarray format. The biochip sensor platform used in this study is based on an oriented streptavidin monolayer that provides a biological interface with well-defined surface architecture that dramatically reduces nonspecific binding interactions. All the antibody or antigen probes were biotinylated and coupled onto streptavidin-coated biochip surfaces (1 $\mu \mathrm{L}$ total volume). The detection limits for the immobilized probes on the microarray surface were $0.5 \mu \mathrm{g} / \mathrm{mL}$ (200 fmol/spot) for the peptide antigen and $0.1 \mu \mathrm{g} / \mathrm{mL}$ (3 fmol/spot) for the recombinant antibodies. Optimal concentrations for the detection of the Cy5labeled protein target were in the range of $20 \mu \mathrm{g} / \mathrm{mL}$. Protein microchips were used to measure antibody-antigen kinetics, to find optimal temperature conditions, and to establish the shelf life of recombinant antibodies immobilized on the streptavidin surface. For recombinant antibody fragments with a kDa of 10-100 nM, we have established an easy and direct immunoassay. In addition, we developed an indirect method for antibody detection with no need for expensive and time-consuming antibody pu-
\end{abstract}

rifications and modifications. Such a method was shown to be useful for largescale screening of recombinant antibody fragments directly after their functional expression in bacteria. Our data demonstrate that recombinant antibody fragments are suitable components in the construction of antibody chips.

\section{INTRODUCTION}

The availability of full genome sequences has generated great interest in studying gene function on a genomewide scale. Several technologies have been developed that allow for the functional analyses of gene activities. DNA arrays are already used extensively as an indirect assay for protein expression by profiling mRNA expression $(3,10,26)$. However, there are several limitations with DNA chip technology that could be addressed by using antibody arrays.

Antibody arrays can be used to analyze the expression of one or more proteins in a mixture such as a cell extract or human serum, with no need to separate the individual components and determine the identity of the corresponding proteins. Although antibodies derived by animal immunization are currently the most widespread class of molecules generally able to serve as high-specificity and high-affinity ligands, such antibody probes can be very expensive. Moreover, classical methods of antibody generation cannot produce these high numbers of different antibodies in a reasonable amount of time. The challenge will be to devise alterna- tive methods such as large phageantibody libraries $(14,28)$ for antibody isolation that are amenable to high throughput and scale up. Thus, recombinant antibody fragments are likely to be the major components in the construction of antibody chips for highthroughput screening of protein expression in human cells. Recombinant antibody fragments provide an excellent target-binding specificity and can be produced in an automated fashion (15). Several groups reported significant progress in developing protein microarray technologies $(2,4,8,22)$ and the use of recombinant antibodies in proteomic (11) and protein microarray technologies $(7,18,25,27)$.

The biochip platform reported here is based on gold-coated glass in a microscope slide format. The immobilization procedure of different molecules onto a gold surface is accomplished by different technologies $(1,9,12,16,20)$. Superior spot-to-spot reproducibility, the elimination of smearing effects, and the prevention of cross talk between adjacent spots are ensured by a hydrophobic Teflon ${ }^{\circledR}$ matrix (13). Recently, this technology was used for the detection of IgM antibodies in the human sera of patients suspected of suffering from Lyme borreliosis (21).

In this study, we wanted to test the chip platform using recombinant antibody fragments. Therefore, either synthetic recombinant antibody fragments ( $\mathrm{scFv}$ and $\mathrm{Fab}$ ) derived from the $\mathrm{Hu}-$ man Combinatorial Antibody Library (HuCAL) system (14) or a synthetic peptide were immobilized onto the streptavidin surface of the biochip plat- 
form. The interactions of either fluorescence-labeled protein antigen or nonlabeled recombinant antibody targets with the surface immobilized probes were monitored in detail by varying a wide range of experimental parameters such as the concentration of the biotinylated probes (to determine the dynamic range) and the reproducibility of interactions and their kinetics. In addition, we developed an indirect immunoassay with no need of antibody labeling or the time-consuming process of antibody purification from periplasmatic extracts.

\section{MATERIALS AND METHODS}

Purified and biotinylated recombinant antibodies Ab27 (scFv), Ab28 (Fab), Ab29 (Fab), and purified nonbiotinylated recombinant antibodies Ab23 (scFv) and $\mathrm{Ab} 24(\mathrm{scFv})$ were provided by MorphoSys AG (Martinsried, Germany). The Ab27, Ab28, and Ab29 are specific to the extracellular part of human recombinant intercellular adhesion molecule 1 (ICAM-1) (R\&D Systems $\mathrm{GmbH}$, Wiesbaden, Germany), while Ab23 and Ab24 recognize a 17-mer peptide M42 (biotin-NH-FTFKEFQNNPNPRSLVK-COOH) derived from the $\alpha$-chain of human integrin CD11b. The M42 peptide antigen was synthesized by ThermoHybaid GmbH (Ulm, Germany) with a purity greater than $93 \%$. The antibodies had been previously generated against the respective antigens by solidphase phage display panning and were selected for this study to allow for comparison of the format ( $\mathrm{scFv}$ and $\mathrm{Fab}$ ) and to compare different affinities, covering a $\mathrm{kDa}$ range from $10^{-8}$ to $10^{-6} \mathrm{M}$. All antibodies are epitope tagged at their Cterminus with the FLAG ${ }^{\circledR}$ tag (DYKDDDDK) (MorphoSys AG) and can be detected using the anti-FLAG M2 monoclonal antibody (Sigma, Deisenhofen, Germany) (6). Goat monoclonal antimouse IgG antibody labeled with $\mathrm{Cy} 5$ dye and the Cy5 monofunctional dye were obtained from Amersham Biosciences (Uppsala, Sweden). Fluorescence labeling of ICAM-1 with Cy5 monofunctional dye was performed according to the manufacturer's instructions. The molecular ratio of ICAM$1 /$ dye was found to be $2: 4$.

\section{Protein Chip Platform}

The protein chip platform, XNA on Gold $^{\mathrm{TM}}$ (ThermoHybaid) is based on nanoscale biocompatible sensor architecture (13). The glass slide is coated primarily with a $0.1-\mu \mathrm{m} 24$ carat gold layer. Layered onto this is a self-assembly monolayer (SAM) and a long chain of thiol-alkanes (16-mercaptohexadecanoic acid), to which biotin is covalently coupled via linker molecules [N-hydroxysuccinimide and 1-ethyl-3(3-dimethylaminopropyl) carbodimide]. Biotin-terminated SAMs are used to immobilize a streptavidin layer with high packing density. The interaction between biotin and streptavidin is strong ( $\mathrm{kDa}$ is approximately $10^{-15} \mathrm{M}$ ), ensuring the integrity of the protein chip surface under a wide range of experimental conditions. The protein chips are designed based on a standard microscope slide format. A duplicate with 96 or 384 spots (i.e., 192 or 768 spots in total), respectively, is available for conducting biomolecular interactions. The individual gold spots of $1.8 \mathrm{~mm}^{2}$ are separated from each other by a Teflon layer. The hydrophobic Teflon surface prevents cross talk between the adjacent spots and virtually eliminates microarray smearing. The chips are compatible with fluorescence, mass spectrometry, and radio-imaging detection schemes.

\section{Direct Immunoassay}

The biotinylated recombinant antibody Ab27, Ab28, and Ab29 probes were dissolved in PBST-BSA buffer [PBS containing $0.1 \%$ Tween ${ }^{\circledR} 20(\mathrm{v} / \mathrm{v})$ and $1 \% \mathrm{BSA}$ ] to obtain a series of concentrations in the range of $0.1-5(\mathrm{Ab} 27$ and $\mathrm{Ab} 28$ ) or $0.1-50 \mu \mathrm{g} / \mathrm{mL}$ (Ab29). A volume of $1 \mu \mathrm{L}$ per spot was used in all experiments, and all samples were manually spotted in duplicate onto each array. The surface immobilization step and all incubations were conducted in a humidified chamber to minimize evaporation effects. After spotting, the humidified case was covered with a tight lid and incubated at room temperature for $60 \mathrm{~min}$ in all experiments, except for the kinetic study (40 min incubation). After immobilization, the chip was rinsed with sterile water, followed 


\section{Research Report}

by three washes for $5 \mathrm{~min}$ in PBST with gentle agitation. Thereafter, the chips were rinsed with sterile water and dried under nitrogen. No blocking reagent was used either during the antigen immobilization or before the target incubation on the chips. The dried chips were immediately used for immunodetection by protein antigen ICAM-1 labeled with Cy5. Direct immunobinding was performed for seven different antigen target concentrations: $\mathrm{a}=100 ; \mathrm{b}=$ $50 ; \mathrm{c}=25 ; \mathrm{d}=12.5 ; \mathrm{e}=6.1 ; \mathrm{f}=3.1$; and $\mathrm{g}=1.6 \mu \mathrm{g} / \mathrm{mL}$ (diluted in PBST

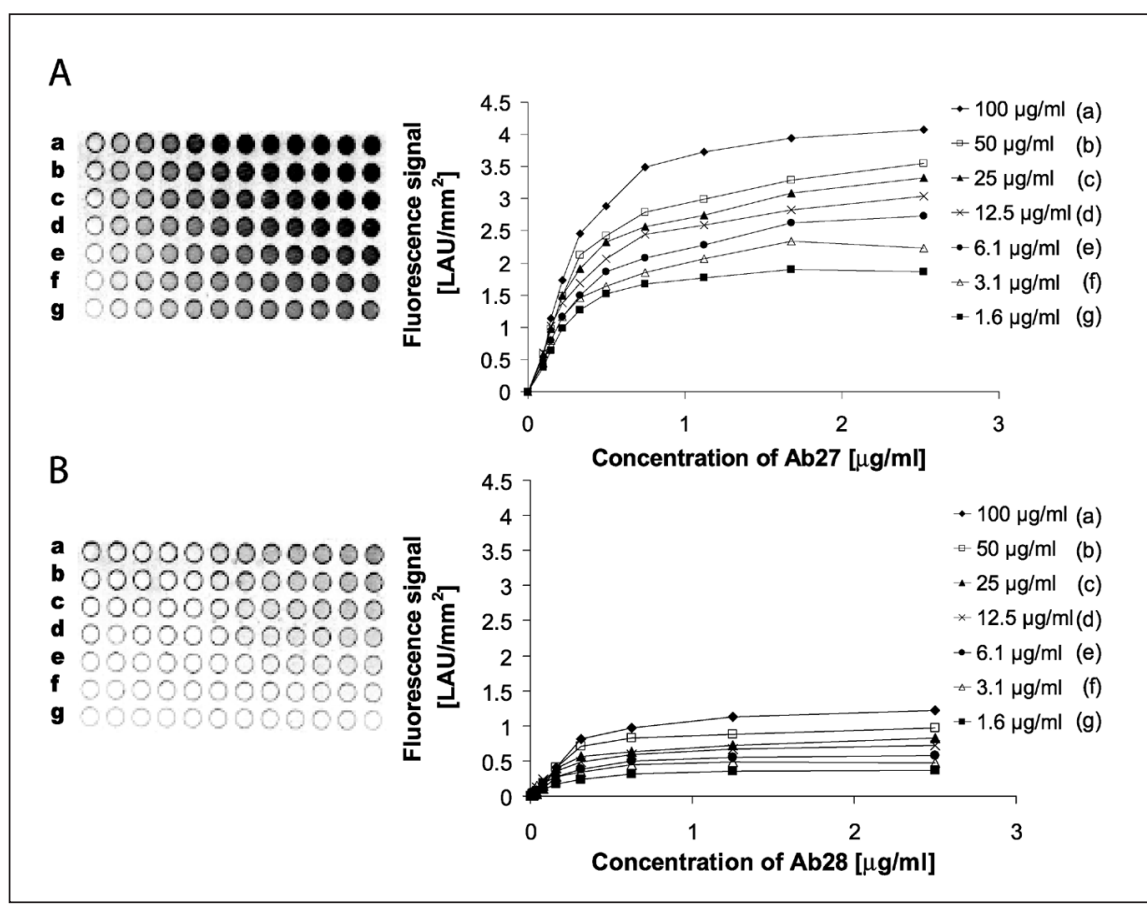

Figure 1. Determination of dynamic ranges of recombinant antibody fragments Ab27 (A) and Ab28 (B) recognizing ICAM-1 labeled with Cy5. The biotinylated antibodies were immobilized onto the streptavidin chip surface at concentrations $0.1-2.5 \mu \mathrm{g} / \mathrm{mL}$ for Ab27 and Ab28. The antibodies were subsequently incubated with the protein antigen ICAM-1-Cy5 at different concentrations (a-g). The antibodies were coated on the chip vertically in columns (12 different concentrations), while the antigen was spotted in horizontal direction ( $\mathrm{a}-\mathrm{g}$; seven different concentrations). buffer) at room temperature for $60 \mathrm{~min}$ in a dark environment unless otherwise stated. The chips were subsequently rinsed with sterile water, followed by three washes for 5 min in PBST with gentle agitation. The chips were then covered with a glass coverslip and scanned using a fluorescence scanner (XNA ScanPro 20 microarray scanner; ThermoHybaid). A helium-neon laser (model configurations: R, RB, RBG types; Fuji Film, Bundoora, Victoria, Australia) (excitation wavelength, 633 $\mathrm{nm}$, and absorption wavelength, 675 $\mathrm{nm}$ ), resolution selections of 16 Bits per pixel, and a $50-\mu \mathrm{m}$ pixel size were chosen for scanning the chips. The microarray analysis software, AIDA 2.11, from Raytest (Straubenhard, Germany) was used to analyze the image files. The fluorescence signal is expressed as linear arbitrary units across a $1-\mathrm{mm}^{2}$ area $\left(\mathrm{LAU} / \mathrm{mm}^{2}\right)$.

\section{Indirect Immunoassay}

The biotinylated peptide M42 probe was dissolved in the PBST buffer to obtain a series of concentrations in the range of $0.5-15 \mu \mathrm{g} / \mathrm{mL}$ ( $1 \mu \mathrm{L}$ final volume). The surface immobilization step for the M42 probe was performed under the same conditions as the immobilization of the biotinylated recombinant antibodies. The dried chips were immediately incubated with purified antibodies Ab23 (Ab24) dissolved in

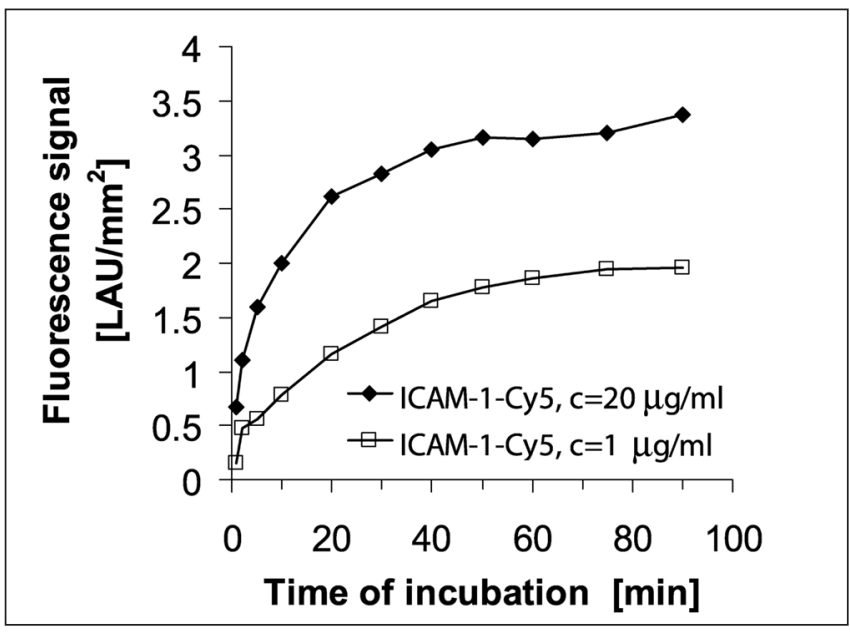

Figure 2. Kinetic study of the Ab27 and ICAM-1-Cy5 interaction using different target concentrations. The immobilized Ab27 (concentration $=1$ $\mu \mathrm{g} / \mathrm{mL}$ ) recombinant antibody was incubated with protein antigen ICAM-1Cy5 for 1, 2, 5, 10, 20, 30, 40, 50, 60, 75, and $90 \mathrm{~min}$. Two concentrations of the ICAM-1-Cy5 (1 and $20 \mu \mathrm{g} / \mathrm{mL})$ were used.

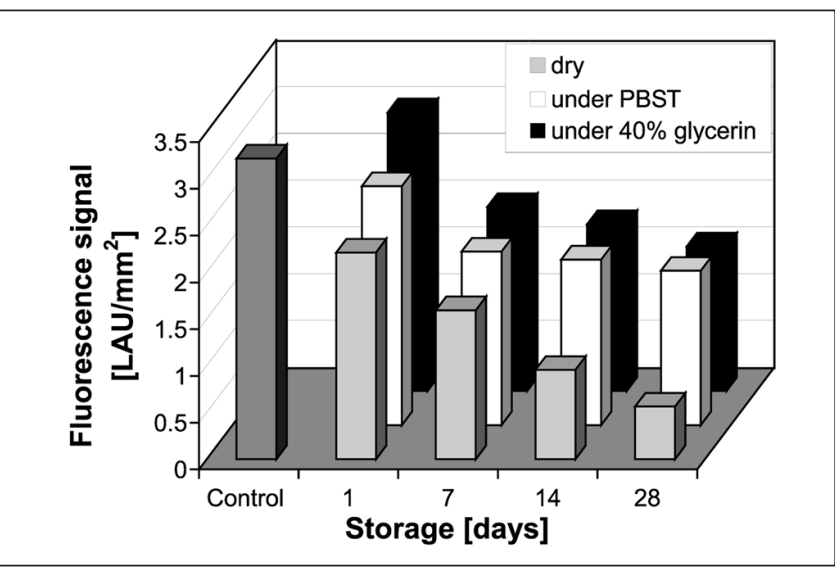

Figure 3. Shelf life of recombinant scFv antibody fragment Ab27. The biotinylated Ab27 (concentration $=1 \mu \mathrm{g} / \mathrm{mL}$ ) was immobilized onto the streptavidin chip surface and stored under different conditions at $4^{\circ} \mathrm{C}$ for $1,7,14$, and 28 days. The chip was stored dry or with PBST buffer or PBST buffer containing $40 \%$ glycerin. The glass coverslip was used to keep solutions on the chip surface. After storage, the chips were evaluated with the protein target ICAM-1-Cy5 (concentration $=20 \mu \mathrm{g} / \mathrm{mL})$ 
Table 1. Reproducibility Analysis of the Protein Chip

\begin{tabular}{|c|c|c|c|c|c|c|c|c|}
\hline \multirow{2}{*}{$\begin{array}{l}c(A b 27) \\
(\mu g / m L)\end{array}$} & \multicolumn{5}{|c|}{ Experiment Nos. (LAU/mm²) } & \multirow[b]{2}{*}{$\overline{\mathbf{x}}$} & \multirow[b]{2}{*}{ SD } & \multirow[b]{2}{*}{ CV (\%) } \\
\hline & 1 & 2 & 3 & 4 & 5 & & & \\
\hline 7.56 & 3.68 & 3.68 & 3.72 & 3.75 & 3.58 & 3.68 & 0.06 & 1.53 \\
\hline 5.04 & 3.65 & 3.53 & 3.69 & 3.54 & 3.55 & 3.59 & 0.07 & 1.86 \\
\hline 3.36 & 3.61 & 3.39 & 3.39 & 3.42 & 3.51 & 3.46 & 0.09 & 2.46 \\
\hline 2.24 & 3.45 & 3.33 & 3.36 & 3.46 & 3.35 & 3.39 & 0.05 & 1.60 \\
\hline 1.49 & 3.35 & 3.04 & 3.17 & 3.26 & 3.25 & 3.21 & 0.10 & 3.18 \\
\hline 1.00 & 3.02 & 2.89 & 3.06 & 3.03 & 2.92 & 2.98 & 0.07 & 2.20 \\
\hline 0.66 & 2.69 & 2.69 & 2.65 & 2.76 & 2.59 & 2.68 & 0.06 & 2.14 \\
\hline 0.44 & 2.45 & 2.40 & 2.15 & 2.30 & 2.35 & 2.33 & 0.10 & 4.44 \\
\hline 0.30 & 2.03 & 2.01 & 1.77 & 2.10 & 1.93 & 1.97 & 0.11 & 5.77 \\
\hline \multicolumn{9}{|c|}{$\begin{array}{l}\text { The effect of the chip-to-chip variability tested by repeating each experiment five } \\
\text { times on five different days. The average values (means), corresponding stan- } \\
\text { dard deviation, and coefficient of variation were calculated. c, concentration. }\end{array}$} \\
\hline
\end{tabular}

PBST-BSA at concentrations between 5 and $100 \mu \mathrm{g} / \mathrm{mL}$ ( $1 \mu \mathrm{L}$ final volume) for $60 \mathrm{~min}$. The chips were subsequently rinsed with sterile water, followed by three washes for $5 \mathrm{~min}$ in PBST with gentle agitation. The chips were subsequently incubated with mouse IgG anti-FLAG M2 monoclonal antibody at room temperature for 30 min (concentration $=20 \mu \mathrm{g} / \mathrm{mL}$ diluted with PBST-BSA; $1 \mu \mathrm{L} / \mathrm{spot}$ ). After three additional washes for $5 \mathrm{~min}$ in PBST with gentle agitation, the chips were incubated with a goat anti-mouse IgG-Cy5 conjugate (diluted 1:500 with PBST-BSA; $1 \mu \mathrm{L} /$ spot) at room temperature for $30 \mathrm{~min}$ in a dark environment. The chips were subsequently rinsed with sterile water, washed three times for 5 min in PBST, covered with a glass coverslip, and detected using the fluorescence scanner.

\section{RESULTS}

\section{Detection of Cy5-Labeled Antigen with Immobilized Antibody Fragments Using the Protein Microarray Platform}

The dynamic range for immobilized recombinant antibodies Ab27 and Ab28 was determined to be $0.1-1$ $\mu \mathrm{g} / \mathrm{mL}$, corresponding to $3-30 \mathrm{fmol}$ Ab27 and 2-20 fmol Ab28 probes per spot (Figure 1, A and B). Higher amounts of immobilized antibody per spot had no significant effect on the final fluorescence signal intensity, which indicated that the saturation levels of the spot surface had been reached. The dynamic range for Ab29 was not determined due to a very weak fluorescence signal. The dissociation constant of the Ab29 antibody, determined previously using surface plasmon resonance (BIAcore, Freiburg, Germany) before modification, was found to be more than 20-fold higher compared to the dissociation constants of Ab27 and Ab28. Drying the antibody-immobilized chip results in approximately $10 \%$ loss of the final fluorescence signal (data not shown). Recombinant antibody probes were incubated with ICAM-1-Cy5 at seven different concentrations (Figure 1, A and $\mathrm{B}, \mathrm{a}-\mathrm{g}$ ) to determine an optimal target concentration. The intensity of the Cy5 signal corresponding to bound ICAM-1 antigen was found to vary in accordance with both the amount of surface-immobilized recombinant antibody probe and with the amount of target added. On the basis of the above 
observation, two ICAM-1-Cy5 antigen concentrations, 1 and $20 \mu \mathrm{g} / \mathrm{mL}$ (18 $\mathrm{nM}$ and $360 \mathrm{nM}$, respectively), were chosen for the following experiments to check for differences in the final fluorescence signals.

\section{Kinetic Study of Recombinant Antibody-Antigen Interactions}

Ab27 antibody was used as the test system for conducting kinetic analysis with its corresponding target. Figure 2 shows the time course of immunobinding of the ICAM-1-Cy5 antigen target with the immobilized Ab27 $(1 \mu \mathrm{g} / \mathrm{mL})$ antibody probe. Half-maximal signal was reached after $9 \mathrm{~min}$, and the signal saturation was reached after 50-60 min if the ICAM-1 concentration was 1 $\mu \mathrm{g} / \mathrm{mL}$. A 20 -fold higher ICAM-1 concentration slightly accelerated the process (5 and $40 \mathrm{~min}$, respectively), and better signal-to-noise ratios were obtained with these target concentrations (data not shown).

\section{Protein Chip Reproducibility}

The effect of the chip-to-chip variability was tested by repeating each experiment five times on five different days. The experiment was based on the incubation of the protein antigen ICAM-1-Cy5 $(20 \mu \mathrm{g} / \mathrm{mL})$ with surfaceimmobilized Ab27 recombinant antibody probe at different concentrations. All dilutions and sample solutions were freshly prepared on the day of the experiment. On the same chip, all test analyses were performed in triplicate, and the average fluorescence signals and standard deviations were calculated for each sample. The coefficient of variation for the fluorescence signals obtained from the values on the different biochips ranged $1.5 \%-$ $5.8 \%$ (Table 1). The intensity of the Cy5 signal corresponding to the ICAM-1 target was found to vary with the Ab27 concentration immobilized on the chips. The results demonstrate that highly reproducible data can be obtained on the streptavidin-coated chips.

\section{Shelf Life of Recombinant Antibodies}

After scFv antibody Ab27 (concentration $=1 \mu \mathrm{g} / \mathrm{mL}$ ) probe immobilization, the chip was stored at $4^{\circ} \mathrm{C}$ for 1,7 , 14 , and 28 days in a dry state or on a glass coverslip containing either PBST buffer or PBST buffer containing 40\% glycerin. After the above storage conditions, detection was performed by using ICAM-1 (concentration = 1 $\mu \mathrm{g} / \mathrm{mL})$. High fluorescence signals were obtained when the Ab27 immobilized chips were stored in $40 \%$ glycerin, whereas storage under dry conditions resulted in decreased fluorescence intensities (Figure 3). Storage in PBST led to intermediate signals, while storage in $40 \%$ glycerin doubled the Ab27 half life from two to four weeks compared to the storage at dry conditions.

\section{Indirect Peptide Antigen Detection by Recombinant Antibodies Ab23 and $\mathrm{Ab24}$}

The dynamic range of the interaction was found to be between 0.5 and 5 $\mu \mathrm{g} / \mathrm{mL}$, which indicated a strong interaction between the streptavidin surface and the biotinylated M42 probe (Figure

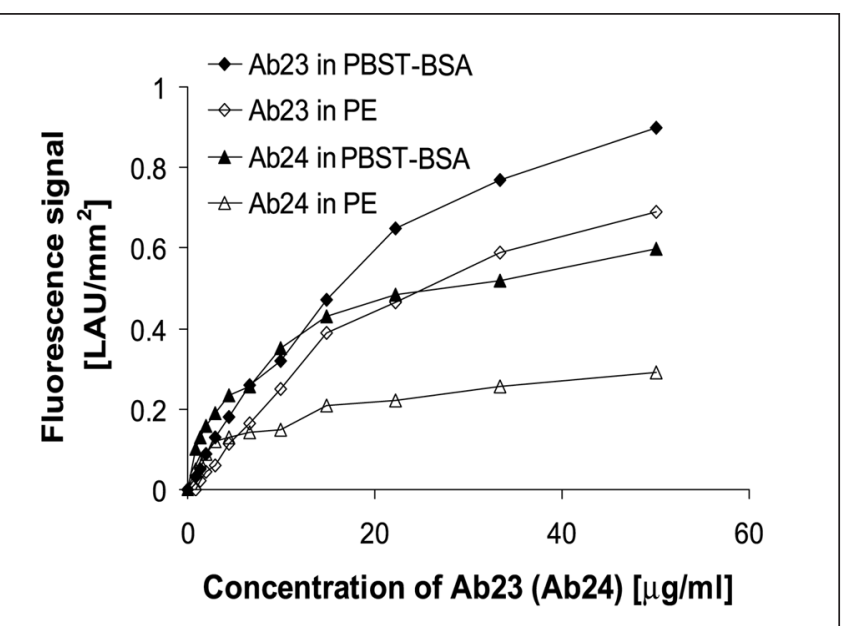

Figure 4. Determination of the dynamic range of antibody peptide interactions using an indirect immunoassay. The biotinylated M42 probe was immobilized onto the streptavidin chip surface at concentrations $0.5-15$ $\mu \mathrm{g} / \mathrm{mL}$ and subsequently incubated with scFv antibody fragments Ab23 (A) or Ab24 (B) at different concentrations $(5,10,25,50,75$, and $100 \mu \mathrm{g} / \mathrm{mL})$. The antibodies Ab23 and Ab24 were detected with the anti-FLAG M2 monoclonal antibody, and visualization was subsequently performed using an antimouse IgG-Cy5 conjugate.

Figure 5. Dynamic range of Ab23 and Ab24 diluted in periplasmatic extracts. The biotinylated M42 $(\mathrm{c}=10 \mu \mathrm{g} / \mathrm{mL})$ probe was immobilized onto the streptavidin chip surface and subsequently incubated with antibody fragments Ab23 or Ab24 diluted with either PBST-BSA or periplasmatic extracts. The antibodies were detected with the anti-FLAG M2 monoclonal antibody, and visualization was performed by an anti-mouse IgG-Cy5 conjugate. PE, periplasmatic extracts. 
4). Compared to the results obtained in the direct immunoassay, a substantial amount of recombinant antibody (approximately 100 and $75 \mu \mathrm{g} / \mathrm{mL} \mathrm{Ab} 23$ and $\mathrm{Ab} 24$, respectively) is required to receive a maximal fluorescence signal. The higher absolute fluorescence signal observed with Ab23 antibody correlates with the higher affinity of this antibody compared to the Ab24 antibody (determined previously using surface plasmon resonance before modification).

\section{Screening of $E$. coli Antibody Expression Using Protein Chips}

Finally, we wanted to test whether our platform can be used to directly screen for recombinant antibody binding using $E$. coli periplasmatic extracts. The Ab23 and Ab24 antibody fragments were serially diluted either in PBST containing 1\% BSA or in E. coli periplasmic extract and incubated on a chip coated with $10 \mathrm{ng}$ M42 peptide antigen (Figure 5). Dilution with the periplasmic extract resulted in lower absolute fluorescence signals compared to the dilution with PBST-BSA, but the dynamic range was comparable. The signals obtained with the periplasmic extract-diluted material are sufficient to directly screen for the binding activity of antibody fragments functionally expressed in E. coli since such extracts usually have an antibody concentration between 10 and $200 \mu \mathrm{g} / \mathrm{mL}$. Such an experiment was performed using periplasmic extract containing unknown amounts of either $\mathrm{Ab} 23$ or Ab24. By comparing fluorescence signals obtained in the experiments with purified antibodies (Figure 5) and signals received in this experiment, we calculated the approximate concentrations of 25 and $30 \mu \mathrm{g} / \mathrm{mL}$ for $\mathrm{Ab} 23$ and Ab24, respectively.

\section{DISCUSSION}

The applicability of microarray technology based on streptavidin surface for the detection of antibody-antigen interactions was analyzed using three different recombinant antibody fragments, Ab27, Ab28, and Ab29, which recognize the soluble extracellular part of human ICAM-1. ICAM-1 is expressed in the endothelium and antigen-presenting cells. Binding to ICAM-1 enables lymphocytes to migrate through blood vessel walls. It has also been found in tissue specimens of artherosclerotic lesions (23). The direct immunoassay was carried out using these antibody fragments fixed onto the biochip platform. Two antibody fragments, Ab23 and $\mathrm{Ab} 24$, specific for a peptide antigen derived from the $\alpha$-chain of human integrin $\mathrm{CD} 11 \mathrm{~b}$ were used to perform an indirect immunobinding. CD11b binds to a wide repertoire of ligands including ICAM-1 $(5,24)$.

Our data show that the direct method is very sensitive because the detection limit was $100 \mathrm{ng} / \mathrm{mL}$ (approximately 3 fmol/spot for recombinant antibodies), with the ICAM-1 antigen target at a concentration of $1 \mu \mathrm{g} / \mathrm{mL}$. In contrast to standard ELISA, only minute amounts $(1 \mu \mathrm{L})$ of all reagents are required to perform a single test. By comparing antibodies against the same antigen but with different affinities, we found a good correlation between signal intensity and binding strength. Standard ELISA experiments indicate that the Cy5-labeling of ICAM-1 does not affect the binding of Ab27 and Ab28 but decreases the Ab29 signal about 2.5-fold, which might explain the very low signals obtained with this antibody. The use of biotin-streptavidin technology enables highly specific interactions and reproducible results. The coefficient of variation was found to be lower than $6 \%$ in a chip-to-chip variability test (Table 1). In addition, there is no need of chip blocking before interaction with a target, which accelerates a typical assay.

The shelf life of immobilized recombinant $\mathrm{scFv}$ antibody fragment Ab27 was demonstrated to be very dependent of storage conditions (Figure $3)$. The beneficial effect of $40 \%$ glycerin as a stabilizing solution has been previously demonstated (17). However, even under such stabilizing conditions, it is not possible to store the scFv-coated chip for several months, as it is possible for DNA microarrays (19). It has to be seen whether other storage conditions or the use of more stable antibody formats (e.g., the Fab format or the disulfide-linked Fv format) will prolong shelf life.

An indirect method to determine an- 
tibody-antigen interactions with no need of antibody modifications was developed in microarray format. Because labeling using a fluorescent dye or biotin is time consuming and can introduce structural changes in the antibody molecule, the indirect immunoassay could be a preferred method. Additionally, the high-throughput screening of recombinant antibodies expressed in $E$. coli grown in microplates can be done directly with this platform since the amount of material required is small (Figures 4 and 5). Although absolute fluorescence signals are somewhat lower with antibodies diluted in periplasmatic extracts (Figure 5), the dynamic range does not change, and the signals are still high enough to measure binding activity.

A main advantage of microarray technology is the reduction of material consumption with no need to increase material concentration. We believe that, for most routine clinical diagnostics and/or scientific purposes, only a few hundred spots per chip will be required. Thus, this chip platform is well suited to these applications.

\section{ACKNOWLEDGMENTS}

We thank Angelika Lüking and Bodo Brocks for critical reading of the manuscript. P.P. wishes to thank the European Commission for a two-year Marie Curie Fellowship (no. QLK2CT-2000-60048)

\section{REFERENCES}

1.Benitez, M.J. and J.S. Jimenez. 2002. A method of reversible biomolecular immobilization for the surface plasmon resonance quantitative analysis of interacting biological macromolecules. Anal. Biochem. 302:161168.

2.Borrebaeck, C.A., S. Ekstrom, A.C. Hager, J. Nilsson, T. Laurell, G. Marko-Varga. 2001. Protein chips based on recombinant antibody fragments: a highly sensitive approach as detected by mass spectrometry. BioTechniques 30:1126-1132.

3.Brown, P.O. and D. Botstein. 1999. Exploring the new world of the genome with DNA microarrays. Nat. Genet. 21:33-37.

4.De Wildt, R.-T., C.R. Mundy, B.D. Gorick, and I.M. Tomlinson. 2000. Antibody arrays for high-throughput screening of antibodyantigen interactions. Nat. Biotechnol. 18:989994.
5.Diamond, M.S., D.E. Staunton, S.D. Marlin, and T.A. Springer. 1991. Binding of the integrin Mac-1 (CD11b/CD18) to the third immunoglobulin-like domain of ICAM-1 (CD54) and its regulation by glycosylation. Cell 65:961-971.

6.Einhauer, A. and A. Jungbauer. 2001. The FLAG peptide, a versatile fusion tag for the purification of recombinant proteins. J. Biochem. Biophys. Methods 49:455-465.

7.Figeys, D. 2002. Adapting arrays and lab-onchip technology for proteomics. Proteomics 2:373-382.

8.Haab, B.B., M.J. Dunham, and P.O. Brown. 2001. Protein micrarrays for highly parallel detection and quantification of specific proteins and antibodies in complex solutions. Genome Biol. 2:0004.1-0004.13.

9.Haseley, S.R., P. Talaga, J.P. Kamerling, and J.F. Vliegenthart. 1999. Characterization of the carbohydrate binding specificity and kinetic parameters of lectins by using surface plasmon resonance. Anal. Biochem. 274:203-210.

10.Hegde, P., R. Qi, K. Abernathy, C. Gay, S. Dharap, R. Gaspard, J.E. Hughes, E. Snesrud, et al. 2000. A concise guide to cDNA microarray analysis. BioTechniques 29:548562.

11.Holt, L.J., C. Enever, R.M. de Wildt, and I.M. Tomlinson. 2000. The use of recombinant antibodies in proteomics. Curr. Opin. Biotechnol. 11:445-449.

12.Horn, I.R., A. Wittinghofer, A.P. de Bruine, and H.R. Hoogenboom. 1999. Selection of phage-displayed fab antibodies on the active conformation of ras yields a high affinity conformation-specific antibody preventing the binding of c-Raf kinase to Ras. FEBS Lett. 463:115-120.

13.Kambhampati, D., W. Du, M. Schäferling, M. Kruschina, M. Cieplik, and F. Ortigao. 2001. XNA on Gold ${ }^{\mathrm{TM}}$ Microarrays: Sensor Platform for Genomic, Proteomic and Glycomic Research. Laborwelt 3:45-46.

14.Knappik, A., L. Ge, A. Honegger, P. Pack, M. Fischer, G. Wellnhofer, A. Hoess, J. Wölle, et al. 2000. Fully synthetic human combinatorial antibody libraries (HuCAL) based on modular consensus frameworks and CDRs randomized with trinucleotides. J. Mol. Biol. 296:57-86.

15.Krebs, B., R. Rauchenberger, S. Reiffert, C. Rothe, M. Tesar, E. Thomassen, M. Cao, T. Dreier, et al. 2001. High-throughput generation and engineering of recombinant human antibodies. J. Immunol. Methods 254:67-84.

16.Kuhn, C., F. Muller, C. Melle, H.P. Nasheuer, F. Janus, W.Deppert, and F. Grosse. 1999. Surface plasmon resonance measurements reveal stable complex formation between p53 and DNA polymerase $\alpha$. Oncogene 18:769-774.

17.MacBeath, G. and S.L. Schreiber. 2000. Printing proteins as microarrays for highthroughput function determination. Science 289:1706-1763.

18.Mirzabekov, A. and A. Kolchinsky. 2001. Emerging array-based technologies in proteomics. Curr. Opin. Chem. Biol. 6:70-75.

19. Mitchell, P. 2002. A perspective on protein microarrays. Nat. Biotechnol. 20:225-229.

20.Mullett W.M., E.P. Lai, and J.M. Yeung. 2000. Surface plasmon resonance-based immunoassays. Methods 22:77-91.

21.Pavlickova, P., N.M. Jensen, H. Paul, M. Schaeferling, C. Giammasi, M. Kruschina, W. Du, M. Theisen, et al. 2002. Antibody detection in human serum using a versatile protein chip platform constructed by applying nanoscale self-assembled architectures on gold. J. Proteome Res. 1:227-231.

22.Robinson, W.H., C. DiGennaro, W. Hueber, B.B. Haab, M. Kamachi, E.J. Dean, S. Fournel, D. Fong, et al. 2002. Autoantigen microarrays for multiplex characterization of autoantibody responses. Nat. Med. 8:295301.

23.Ross, R. 1999. Atherosclerosis-an inflammatory disease. N. Engl. J. Med. 340:115-126.

24.Smith, C.W., S.D. Marlin, R. Rothlein, C. Toman, and D.C. Anderson. 1989. Cooperative interactions of LFA-1 and Mac-1 with intercellular adhesion molecule- 1 in facilitating adherence and transendothelial migration of human neutrophils in vitro. J. Clin. Invest. 83:2008-2017.

25.Templin, M.F., D. Stoll, M. Schrenk, P.C Traub, C.F. Vohringer, and T.O. Joos. 2002 Protein microarray technology. Trends Biotechnol. 20:160-166.

26.van't Veer, L.J., H. Dai, M.J. van de Vijver, Y.D. He, A.A. Hart, M. Mao, H.L. Peterse K. van der Kooy, et al. 2002. Gene expression profiling predicts clinical outcome of breast cancer. Nature 415:530-536.

27.Wilson, D.S. and N. Steffen. 2001. Functional protein microarrays. Curr. Opin. Chem. Biol. 6:81-85.

28.Winter, G., A.D. Griffiths, R.E. Hawkins, and H.R. Hoogenboom. 1994. Making antibodies by phage display technology. Annu. Rev. Immunol. 12:433-455.

Received 23 August 2002; accepted 25 October 2002.

Address correspondence to:

Dr. Hubert Hug

TheraSTrat $A G$

Gewerbestrasse 25

CH-4123 Allschwil, Switzerland

\section{For reprints of this or any other article, contact} Reprints@BioTechniques.com 